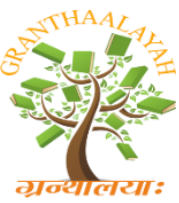

$$
\begin{aligned}
& \text { INTERNATIONAL JOURNAL OF RESEARCH - } \\
& \text { GRANTHAALAYAH } \\
& \text { A knowledge Repository }
\end{aligned}
$$

Science

\title{
NEW TEACHING MATHEMATICS TEACHING EFFECTIVENESS OF THE USE OF INFORMATION AND COMMUNICATION TECHNOLOGIES
}

\author{
Zhanys Aray Boshanqyzy ${ }^{1}$, Nurkasymova Saule Nurkasymovna ${ }^{2}$ \\ ${ }^{1}$ Ph.D. PCBs, Professor Russian Academy of Natural number 7524, Head of Department of \\ Information Systems and Computer Science, Kokshetau University named after Abay \\ Myrzahmetova \\ ${ }^{2}$ Doctor of Pedagogical Sciences, Professor Eurasian National University by Name is \\ L.N.Gumilyov. Republic of Kazakhstan, Astana
}

DOI: https://doi.org/10.29121/granthaalayah.v5.i1.2017.1885

\begin{abstract}
The possibilities of computer technologies in improving the quality of teaching mathematics and its application in the 7th grade students studied the impact on the development of mathematical thinking. Teachers and pupils kanşalıktı methodology to apply this technology meñgergendikteri tested and determined to improve the methods of teaching mathematics in the scientific literature of the main ideas, 7th grade, based on the best practices in the teaching of mathematics and taking into account the requirements set by the company's mastery of mathematical concepts and rules and reports identified the role of the computer in teaching and service, including through the effective use of the computer are determined based on the study of the material should be studied.
\end{abstract}

Keywords: Government Programs; Training; Aqpparattandırw; Information and Communication Technologies; Information and Control Over the Organization of the Learning Process Development; Automation; Illustrations; Tools; Charts Diagrams; Mathematical Formwlwlar Introduction of Mathematical Modules; Hypertext; Interactive Whiteboards; The Internet; EMathematical Definitions.

Cite This Article: Zhanys Aray Boshanqyzy, and Nurkasymova Saule Nurkasymovna. (2017). "NEW TEACHING MATHEMATICS TEACHING EFFECTIVENESS OF THE USE OF INFORMATION AND COMMUNICATION TECHNOLOGIES.” International Journal of Research - Granthaalayah, 5(1), 214-229. 10.29121/granthaalayah.v5.i1.2017.1885.

\section{Introduction}

The peculiarity of the current education system - not only education, but with the development of self-education arm, creating the need for continued progress on their own. 
The widespread use of information and communication technologies in the educational process of the state program was noted as one of the main directions of development of general education. The main purpose of the information system of secondary education students' information culture. This target can perform the work of students in teacher education process subjects dialog mode. Modern information technology to every student in the learning process clear opportunities for the development of creative abilities. This is the information technology and to allow every student to choose the path of self-education training programs to create a system of public education programming and maintaining the integrity of the educational process at the expense of changing beyimdelinwi on the basis of the property it is important to allow individualization of computer teaching students through the effective organization of the process of cognitive activity education is associated with a radical change of technology [1].

High school student culture is very important to provide the opportunity to explain the basis for the development of information laws. Therefore, the school is currently fundamental subjects, including mathematics, and computerization of training, the organization of the educational process is one of the main problems [2].

New teaching of mathematics teaching the main purpose of the use of information and communication technologies to assist in the process of education pupils. For this purpose, training programs, lectures to support e-books, software programs, such as checking products serves [3].

Information technology in teaching mathematics and teaching purposes:

- Fast connection between the user and the information and communication devices;

- Taught computer elestetilwi the source of the information;

- The automation of the control of the organization of information and learning methods.

Methods of teaching mathematics students to form its own personality, its outlook to continue to study subjects related to the development of intelligence and knowledge, and mathematical knowledge and skills necessary for future professional formation and systematization. However, in most cases the various departments of the teacher and do not have time visual display of the discussions. Write-off of a certain type on the basis of the teacher's attention will be spent on practical skills [4].

Currently mathematics lessons is not enough to only be used for testing for illustrative purposes only. Computer classes to be applied at all stages of the educational process explanatory statement, once again, the knowledge, skills, abilities and performance testing and verifying the use of information technology to improve students' knowledge; First, to improve the performance of the teacher, helps to devote more time to examine the results of the study; Observing the second objective assessment of children's knowledge; Enter the third scientific älementter control technology from educational institutions so that you can use it later to talk about specific levels of education and skills certification technologies can serve as a basis [5].

The basis of this process is the result of the verification of the teachers with detailed information about the children in addition to their written down on paper due to an error in each task. These are the result of another computer test will be inspected, or teacher. The main goal is not to 
student assessment test that provides information about a student's knowledge of what topic didactic.

Can be embedded in several disciplines of mathematics and computer science classes. "Microsoft Office" as part of a package of "MS Excel" program of education and technology was established. The main reason to pay attention to this program is determined by the following features:

- $\quad$ "MS Excel" instrumental grouped effective means of special panels assembled and allows you to perform different actions;

To the powerful formulas and functions;

- The first change data to automate the variables related to the restatement of hard work to provide value in the form of a table;

Changes in the various data using graphs and charts, and their beautiful, clear image.

These themes are:

- $\quad$ arithmetic (geometric) Find the sum of progression and a member of the n-th;

- construction of quadratic functions, graphs and research;

- Cramer method of solving a system of linear equations;

Two of solving the system of equations with variable;

- integral calculus.

At the same capabilities of information technology implemented in practice to improve the creative abilities of students in the learning process, formation and development of information and culture, for the effective organization of educational process in order to customize their cognitive activity can be summarized as the following considerations:

- The computer does not fragment the educational process should be continuous;

- requiring large amounts of programming and "quick eskiretin" personal computer programs gone, the use of certain mathematical packages only need to equip a new methodological content;

- $\quad$ satisfy certain conditions need to be methodical support and software;

- Computer workshop provides the active role of the teacher and student;

- instrumental spiritual connection with the aging of the environment;

- additions and changes to flexible.

At the time of the subsequent research demonstrates the successful use of the computer in teaching mathematics. Studies have proven to increase the efficiency of the computer as a tool for the teacher's assistant training. As well as computer classes in the different levels of each student in the course of carrying out tasks, and taking into account the progress of groups of students, which allows you to keep track of total points earned.

At present, the theory of textbooks, teaching methodology for the design of a new information technology is being developed. The interest of teachers in the process of computerization of the process of teaching the theory of creative search älektrond 1 books and create a desire to learn how to use their practice. Compliance with e-books feature modwldikke students should learn the high mobility and flexibility. This educational, research and educational tool.

Effectiveness of e-books is as follows: 
- allows you to quickly find the information materials;

- hypertext comprehensive interpretation of informational materials;

- theoretical material to study to learn to read on their own;

- The lesson will help you as illustrative material supply;

- At the classroom and outside the classroom on their own allows you to perform various segments of the creative tasks;

- stages of preparation for the exam.

- Currently in the process of being taken computer training "interactive whiteboard" to work with. The effectiveness of the board:

- provides feedback as soon as possible;

- allows you to quickly find the information materials;

- each individual's knowledge, skills and abilities to evaluate the check for each chapter.

Teacher lectures on the subject of the first computers in the classroom and practical laboratory work to develop your own theme contents of the reports, will enter to verify the student's knowledge of the tests. PC changes to the text of the lecture will be the introduction of additional materials and effort. Students will learn about changes in a timely manner.

Each teacher on the subject of his lecture material and practical lessons, with the advantages of signing into the final test of the control computer. It is a first for various reasons did not attend the rest of the student reading achievement computer search functionality, access to education. Secondly, the use of a personal computer, the graphic is of interest to the student discipline and the ability to accumulate enough knowledge to learn the lessons. Third, the different levels of education assumed a new class of students took part in training. Fourth, the students of using a computer lesson knowing the logical structure of the module can plan in advance to perform tasks [6].

Thus, the use of the computer in the process of teaching mathematics conclusions can be summarized as follows:

- Computer business approach to the organization of the educational process, adequate technical means;

- Computer into the role of an active partner of the students' action increases the motivation, individual training process is carried out;

- Computer software without affecting the integrity of the process of teaching mathematics and opens the way for the organization, taking into account the individual characteristics of the students will be able to find the desired information tasks;

- Computer-assisted learning tool for unprecedented control over the organization and new information technologies students may use during the lesson, for example;

- The computer made in our understanding of the process of normalization of the students, their logic and raises the level of mental retardation;

- The ability to build complex image of the computer as a high level of visibility improved learning material;

- Computer introduces new educational tools in the learning process.

- In today's world, the development of information technology kommwnakatïvtik each individual qualities such as the ability to read and write in a row and has become a 
prerequisite for everyone. Knowledge and skills further defines the ways of development of society in many cases [7].

The basis of a guarantee of the future of the country and the use of information technology to improve the level of education in schools to improve the educational process to the appropriate level, teachers, managers believe that it is guided by the teaching staff on a regular route.

At present tekékonomïkalıq and not only in the political process, education system, information technology began to be used widely.

Information technology and computer network has been expanded through the use of new educational methods. The most important application of new information technologies in the education system faktoriana most important factor in the application of information technology in the education system main driving force of the driving force of the people, therefore, should be the implementation of the basic principles of education. In this regard, you must create the necessary conditions for the development of the creative potential of the person. As a result of the use of new information technologies in the system of higher education institutions, itself become a person trained in human potential is clear.

"The new communication technologies in the field of education," the concept of computer technology and electronic information systems, and there's always new teaching methods izdenwinen.

The main purpose of the use of new communication technologies in teaching mathematics students to help in the process of education. For this purpose, training programs, lectures to support e-books, software programs, such as checking products.

Future, people are not only competent, but also the "second" must also be computer literacy.

Students are expected to form their own educational phenomena in the process of information collection, processing, and implement modern information technologies in the field of development.

Therefore, the training of teachers of subjects not only for use in teaching computer science courses, as well as information on specific disciplines should pay special attention to the implementation of the technology.

Mathematics teachers need to know the following:

Various objects rendering, put it on display for the construction and implementation of dynamic elestetilwin;

- calculation process, work in the search for information, as well as data collection, processing and automation of trained objects, phenomena, processes, information collection;

- In addition to the use of information technology in the teaching of mathematics education;

- The main criteria to assess the level of students' knowledge; 
- the user's knowledge, to assess the readiness of the ability to use a computer test and diagnostic methods.

At the same time, mathematics teachers in their professional lives can be divided into the following main areas:

1) The purpose of information technology in the teaching of mathematics teaching:

a. fast connection between the user and the information and communication devices;

b. information on teaching computers elestetilwi eyes;

c. the organization of the learning process control automation methods.

2) Local and general information and communication network.

3) Training and education in terms of knowledge of the process of informing features, as well as the methodology applied in practice, including statistical information systems.

4) The electronic structure of the instruments, applications, engineering and estimation know the value of content and methodical.

5) Electronic computing, information and communication tools methodical ärgonomïkalıq conditions.

6) In the tests, the use of computer diagnostic features, including the identification and assessment of the level of students' knowledge, as well as monitoring and assessment of their knowledge.

In this regard, the implementation of quality education, modular implementation of the program.

He was able to change the contents of the blocks in different combinations for each class of students, and can be used at any time. He should be able to make changes in the program to open. In addition, each topic should be divided into separate modules. Each unit was in the form of a specific module on the right. [7].

The computer is an educational tool for students and teachers in the field of education workers. It shall be effective before the full software for teachers and students how to achieve this objective and must be provided.

Computer training software for the use of technology (e-books, etc.) effective use of teachers in class search experience, teaching skills required. During the introduction of computer technologies created a computer algorithm support structure of the lesson. The following stages:

1) The formation of the script (computer classes with a specific structure: a screen type, the teacher action, school action, result);

2) The calculation of the time period of each lesson;

3) The purpose of the lesson, objectives, practical tasks and methods of their implementation of the necessary software.

One of the advantages of the use of computer technology during the lesson:

- colorful animations, pictures, etc. Remember beneficial to the process;

- The student's self-organizes and manages the work of the computer;

- carries out the work of individual pupil;

- Computer training is associated with the success of the possibilities of audio and video equipment; 
- Each lesson includes the following;

- continuous language to communicate with the computer;

- several times to exercise the skills learned to read and listen to the material by repeating the meñgertiledi;

- ätalonniñ regularly to students at all stages of the operation consists of sound bites and speech sound ätalonmen mapping.

Thus, the provision of quality education in new technologies currently being used abundantly, but benefit from the ability to use the convenience of students to each teacher. Pedagogical relationship between technology and teaching skill. Teaching a very good level of knowledge of the technology. Therefore, various technologies in the learning content and training young and psychological characteristics of students, in practice, a critical consideration the importance of the teacher's actions.

Using new technologies for deep education of the students, the following principles should be kept in mind:

1) The teacher just know it deep enough to discipline children should be in line with the very simple life.

2) The student personal psychology (soul) know to reach every student should be able to find a way to the heart.

3) The teacher for every student should be able to claim the entire class.

4) In each lesson the teacher know the correct application of science and technology jañaliqtarn.

5) To the extent possible, some of the big themes of the group, personal knowledge of the group in the form of blocks.

6) In order to improve the children's ability to remember new classes on the basis of the reference notes and personal support.

7) To increase the children's interest in the discipline in the classroom use of various interesting elements.

8) Each lesson must pass their classes.

Students a certain degree of education and training, to increase degenintasin each teacher to learn. During the lesson, the students knowledge to work quştarlığınarttırw training, the sense of responsibility among students is a key requirement qalıptastırwmuğalimge. E-books is paydasıöte addressing this requirement.

The main objective of the current education system Kazakhstani students studying national and universal moral values of science and technology to raise the level of the individual achievements of abstract knowledge and skills, but also to use part of their life [19]. Wide field of science and technology every year, which is the basis of the rapid development of education affect the primary school. According to today's elementary school students work on their own development and use of new information technologies in the development of creative abilities and has become a key problem is the provision of an effective method. The effectiveness of the new information technology teacher bastawıştağ to expand students' knowledge of the world and create conditions for the full development of the ability to see it. At the same time, the main 
features of the new information technologies on their own to see the results of their work for the students to be self-critical attitude.

The new technology is a tool to revitalize the possibility of a teacher. During the lesson the new information technologies to increase students' interest in the subject. And it has several advantages. In the course of teaching these benefits, and lessons can also view the results:

1) The students read about the phenomena and objects with complete and accurate information, and improve the quality of education;

2) To increase the study of teaching students to reach difficult to explain visual materials;

3) To increase the effectiveness of teaching and learning increases the opportunity to explain the material;

4) The student with the formation of a scientific and philosophical point of view, to meet the needs of their natural curiosity;

5) The release of technical work of teachers, ünemdengen create conditions for their creative work;

6) To facilitate the work of teachers and students.

Deepening of integration processes in the area of education in the world is unquestionably one of the most progressive of the relevant information technologies. During this period, developed a high degree of qualification, knowledge itself competitive on the international labor fair for professional training can feel free to walk is one of the most important educational institutions of Kazakhstan.

Quality of education currently in the organization of the work of students, greater use of new techniques and technologies require awareness education.

In addition to the use of information technology and systems already using constant contact with non-traditional systems, are only effective in the new capabilities of the participants in the learning process [9].

Various format files, databases, software modules, a collection of individual programs and programs may be subject areas, as well as specific feature may not be available, depending on the scope and tasks. The basic requirements stored in the software based on the use of the process of education, natural light and student training to become acquainted with the materials of the light. Programs that meet the requirements and characteristics of HCI (in English "Human Computer Interface" and "human-computer interface") adopted by abrevïatwrasimen. This is a literal translation of the word "computer programs for an interview with" understanding [9].

Despite the shortcomings in the conditions of informatization of education, the "information revolution" can be called as available income are as follows:

- a new form for submission of information. Interesting, live or pre-recorded multimedia information, text, graphics, animation, audio and video accounts tool is available via the Internet or other telecommunication means are recorded on compact discs; 
New libraries. Intellectual resources and income increases. Internet electronic library catalogs together, regardless of the distance and time difference to collect a huge amount of information available. Of course, this does not give full access to the information stored in the libraries;

New forms of training sessions. Students and teachers work together during a virtual workshops and laboratories, as well as a new opportunity to synchronous. This was for a number of students more convenient, because the traditional forms of training, their capabilities, their preferred work schedule and opening remarks met with more than interesting;

- The structure of the new knowledge. Today, the education system should be supplemented by a new structure for telecommunications systems, as well as information and communication technologies in the process of education must be highly skilled.

Mostly distance learning programs intended to achieve the most abundant and demands more than the quality of education is not clear. The program was carried out to improve the quality of education will be the development of a number of mandatory requirements:

- The quality and the possibility of higher education space, the center of the conventional institutions offering higher education opportunities;

- on the Internet, the creation of a universal library computer users at any time should the library and the usual amount of information available;

- The network of relationships with teachers;

- teacher and student to create a system of checks and computer knowledge.

The following basic quality education can be achieved under the conditions:

- The use of expensive technologies and software products;

- The integration of full-time and distance learning;

- directories make it easy to find the necessary information resources.

One of the main directions of the state program to inform the system of secondary education the process of learning information. Implementation of this direction is necessary to draw a new generation of textbooks for the electronic version.

New information technologies in education is the process of preparing information and student.

The main purpose of the use of information technology in the classroom: the creation of a unified educational information environment in the Republic of Kazakhstan, the world information space of the Republic of Kazakhstan, the use of new information technologies in educational space continuity [10].

The main objectives of the information technologies:

- The use of information technology in the classroom;

- identify practical measures;

- carry out research and teaching;

The principles of information technology:

- Intellectual and creative abilities of the individual; 
- The clarity of the information obtained through the knowledge and process equipment;

- a series of education and training;

General computer literacy;

- The speed of training and education.

The key link mathematics to develop students' ability to think and create. It is the students' intelligence, logical thinking and creativity will contribute to fully understand [11].

Information technology student teaching mathematics concepts taught deep, but motivates students to develop a sense of émocïyasina game. Select the source of the information and the contents of the necessary information for independent thinking and decision-making skills.

The decision of the United Nations "in the twenty-first century information age" was called. Each lesson, students along with the use of new information technologies is aimed at the development of the following skills:

1) education, increasing interest in the development of skills;

2) The responsibilities and duties;

3) The reporting and analysis skills;

4) The development of information and logical thinking;

5) teach their own research and computer literacy education;

6) The ability to apply the knowledge gained in education.

Serves as a tool for learning new information technology tools.

1 in accordance with the new information technology tools.

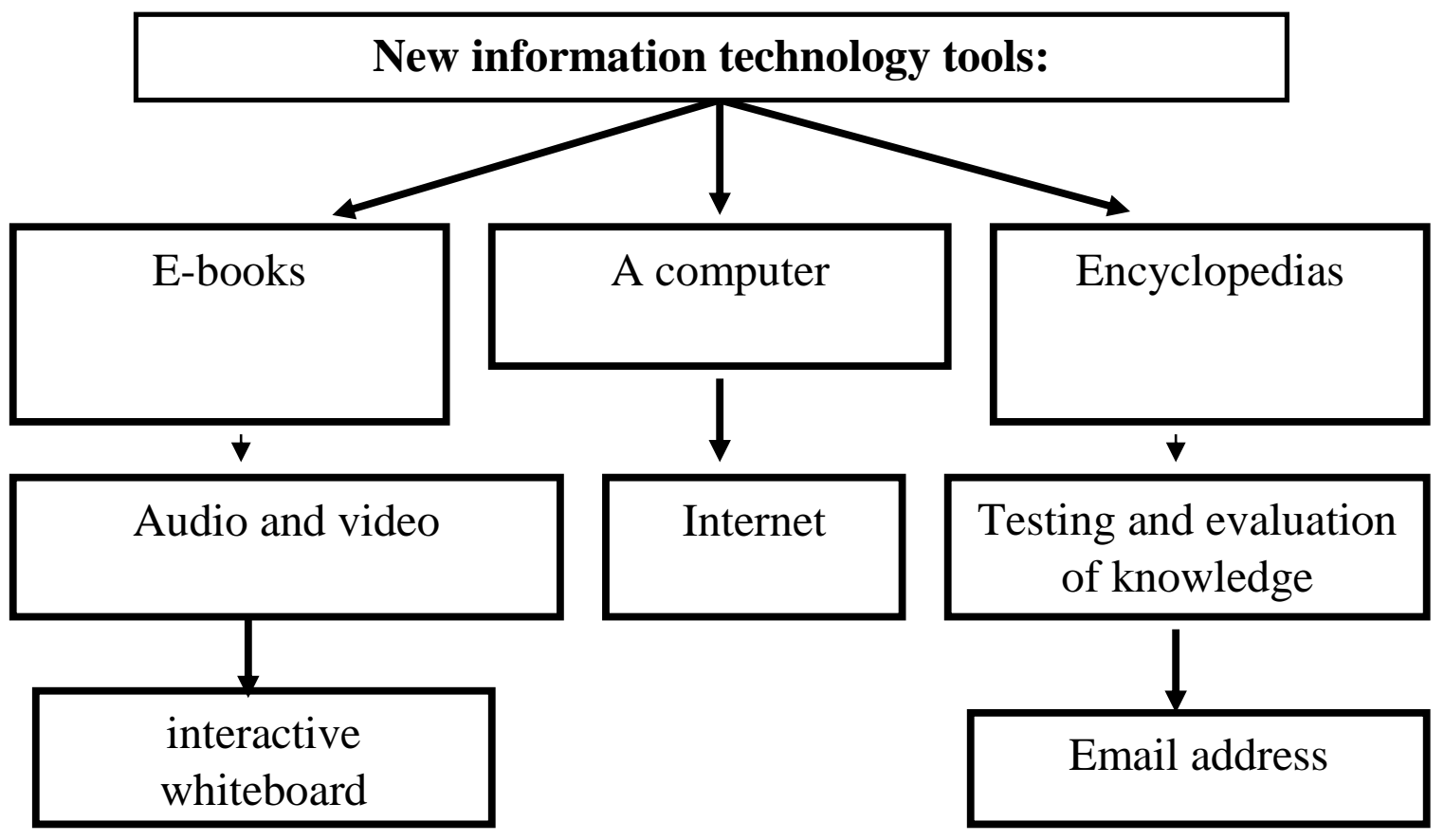

Figure 1: New information technology tools 
Mathematics is a mental field, thinking, and develop the ability to analyze the development of the treasures of knowledge, especially in the study of teaching mathematics consistent, persistent, but also requires hard work. Therefore, all the systematic training of students is not possible to show a good result [12].

Mathematics teacher preparing students for part-time state controls have to explain its approach to the subject of mathematics and statistics system, or considered only as a measuring tool of any science to explain that in the first place, and secondly, any claim to have students showed their strength and meñgeretiñdigi create in their feelings about the present stage, the most difficult psychologically to know that the purpose of the school is very reasonable.

Math teacher by day-to-day activities of scientific style, morality, self-critical view, but also adapts to the responsibility and loyalty. These properties honored students and temporary difficulties in the future will be resistant to the psychological discomfort [13].

Informatization of the education system through the use of new information technologies in the field of developmental education, the implementation of the objectives of the individual-oriented teaching, training aims to improve the quality and efficiency at all levels of the educational process.

The computer is one of the most effective means of training used in the learning process. It does not define the contents and methods of teaching.

Computer technology means teaching students the process of preparation and submission of information by computer. Computer technology is subject to a variety of teaching methods: software training, educational training, etc. [14].

Currently, every modern man knows the computer use at work and at home. Modern computer technology allows us to solve large-scale problems in the world, will help us to handle a large number of information within a very short period of time.

The speed of development of the computer components only in the mathematical, not only remove the graphic reports.

To date, the video and audio information processing and creation of videos is not the most difficult.

Computer-based training and technical education is one of the tools is the use of a computer. It offers e-learning specialist to name some of the scientists in the future. Receptive and interactive e-learning system is divided into two.

The use of an interactive system for personal computers, video recorders, video disc, or on the basis of TV sets created, trained and equipment will be on bilateral relations between the visual and provide feedback. 
If so, the new information technology training, technical and human resources, and taking into account the interaction between the learning receptive to optimize the implementation of elearning or interactive type and can be considered as a systematic method [15].

Module - this is the logic of the end of the block. Size may correspond to the theme, but the difference module objectives, goals and levels of skills and abilities are clearly defined. Basic concepts, skills development of educational materials for module list of selected price category with the standards of quality of education delivered. That is, the analysis of the level of educational material in preparation for the selection. Modular learning opportunities for the best students in each category of the development tasks.

At present, the level of development of computer technology, multimedia communications capabilities and benefits of a new era full of high-quality, real prerequisites.

Thus the theme of lesson books use the extra material increases students' horizons, foreign partners will help to understand easily.

Efficient use of information technology in mathematics lessons will lead to an increase in the quality of education. In mathematics lessons with the use of new information technologies to increase the interest of the students' knowledge skills, the ability to analyze it from the reports of various levels have been trained. Figure 2 provides the concept of information technology.

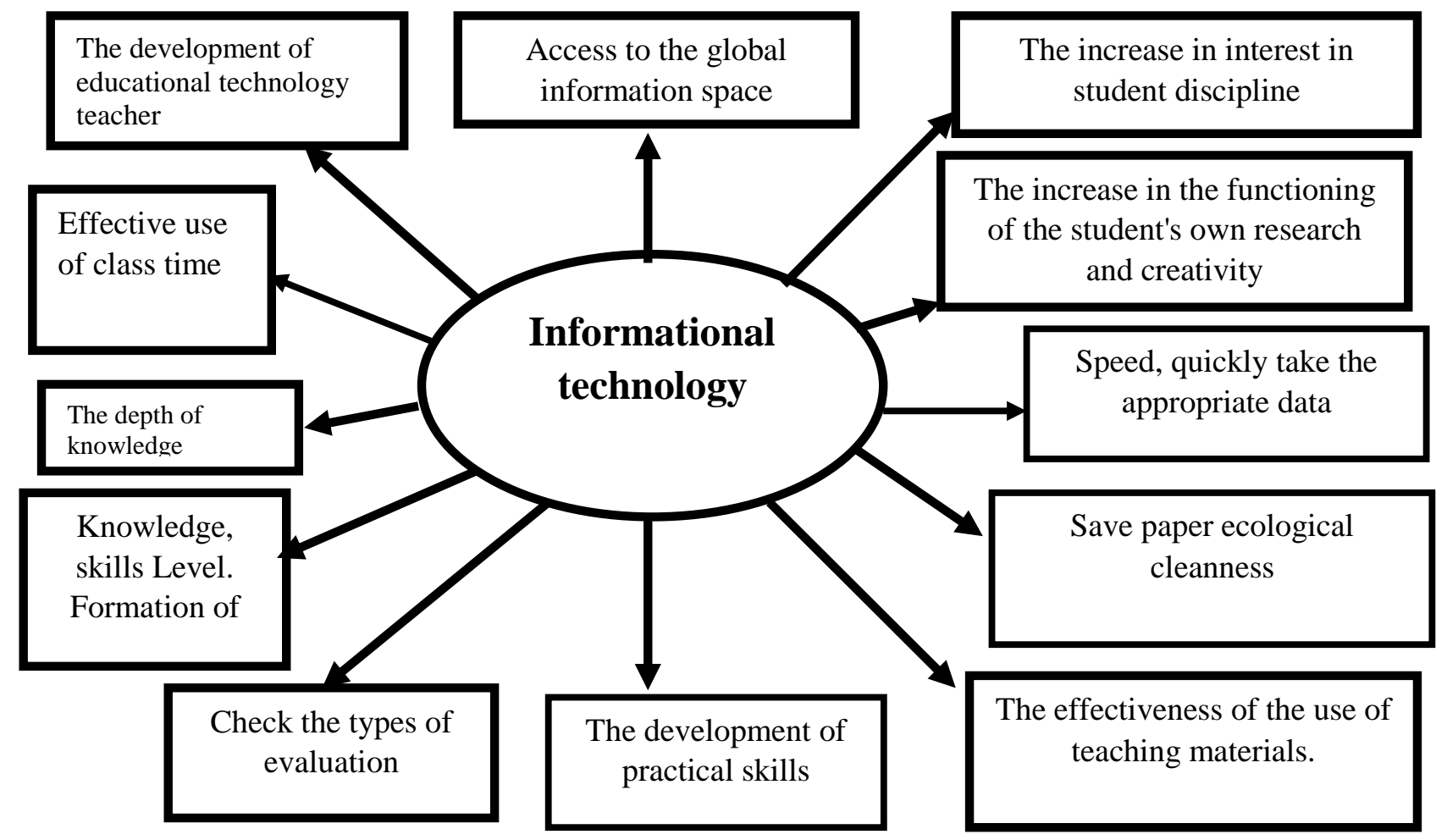

Figure 2: The concept of information technology 
Currently, the classification of the automated training system. However, depending on the purpose of their implementation techniques of computer-based training programs are in the middle of the following types:

1) The skills and business training programs designed to secure and to prepare themselves and of education. When you use these programs, expected to know the theoretical material oqitilatındar;

2) The observer program is designed to control the level of education or business. As is known, take control of the knowledge of education is one of the most important characteristics of the organization and at the same time the level of research and theoretical learning process chain of the worst. The main disadvantage is that the forms and methods of control: they are, in most cases, price stability and the quality of training to master the information necessary invarïanttıllğın and this does not ensure the adequacy of the price level of knowledge of the truth. The problem of the improvement of the educational process control node assembly knowledge and skills around the issue of price increase aqïqatınıñ koncentracïyalanw1. This problem can be seen in two aspects: first: of education as an increase in the price of all levels of education and teaching degree; Second: The following control methods of assembly and distribution method, the cost of the teacher's subjective setup and random factors is to ensure independent. According to the results of the monitoring program schedules of teaching and teacher will allow to increase the efficiency of labor, as well as teachers are required to monitor the stability and subjective setup independent;

3) The advantage of learning new concepts based mentoring programs. Learning from these programs in the form of a dialogue, but a large part of the dialogue oqit1latınniñ or modification is based on the actual dialogue is the answer;

4) The program is designed to explain the visual display an educational material. When the teacher explained the new material will be able to use the computer as a successful visual aids. During the dialogue or the intensification of the educational process, there are great opportunities in the use of interactive graphics programs;

5) information assigned to the necessary information and referral programs. While reading prepared to be taught in the future, or other computers via modem and telephone line, and the use of a personal computer connected to the library. In this case, the publication of a computerized catalog of the book or periodical, which has access to the necessary information. Computer-assisted information organized by the students will be able to organize the data warehouse, there are many different bank relationships. The Encyclopedia is important to know how to use the library or computer so that the portion of the information you need to know;

6) simulation and modeling programs, facilities and events "simulation" to the destination.

If your event is not possible or difficult to implement these very important programs. This abstract concept in the application of specific programs will be made easier because of education. In addition, the students have mastered the material than just remember the massive information köpbilim.

In conclusion, using your computer, math classes, interpretation, training, evaluation and correction can be carried out. The teacher of mathematics teaching to achieve a certain result, 
computer equipment after using the effective teaching of mathematics lesson clear that access to quality education.

Learning environment development tools.

Serve as a tool for learning new information technology tools. Listener-field materials other than traditional schools are recommended:

- computer training programs;

- e-learning;

- The computer control system of testing and knowledge;

- Electronic reference books and encyclopedias;

- Audio and video;

- Internet network information materials.

This accelerated development of educational materials and tools beneficial impact on improving the quality of teaching.

Distance learning materials should be based authoring tools. A long process of development of teaching aids. The development of educational tools to improve the effectiveness of the form of distance learning is the main source [16].

Distance learning and technical base.

Distance learning facilities (telephone and telecommunication channels, television and radio) is a system of private information.

Information resources of the Internet: E-Mail, WWW.

\section{Forms.}

The use of a variety of personal training program information, can be a different kind of level and consisted of the following:

- the implementation of the individual tasks in the classroom;

- The rest of the electronic instrument module (new education, training, laboratory work, tests);

- älektrondiq academic course books on self-development.

- Group forms.

- the development of forms of individual training basqajaña appear on the form that is compatible with your computer training;

- The emergence of computer networks of various schools, students, even in areas of the house, leaving the office to work compatible with each other;

- The computer can be used in all types of educational process.

- A new interpretation of the material (in the preamble);

- approval;

- Repeat;

- checks. 
The use of ICT options:

- The teacher's action, computer software, a complete replacement of the e-reader on the subject;

- The teacher's computer-based training program of action (subject of personal issues, questions) semiconductors;

Additional material sample, the use of custom audio vïdeokörnekilikter, electronic anthologies, encyclopedias, museums, in addition to a set of monitors and other educational materials [17].

The use of ICT options:

- use of training programs for the approval of the material;

- diagnostic and control materials;

- students for work in the classroom or outside the classroom performance of independent and art house.

The use of ICT options:

- The application for the construction of a computer graphic;

- laboratory show programs ( "Matlab" and other programs);

- approval of the material, motivation, psychological training game and interesting programs.

Mathematical system of education to students, the ability to apply their knowledge and bringing up the development of a special teacher. Teacher good the whole way of life and morality, moral and spiritual debt.

The purpose of the teachers using all components of teaching students in-depth knowledge at the level of general secondary education.

Each student a comprehensive knowledge of education is the main task of every teacher. Mathematics and Science powerful.

Modern mathematical spread very versatile stage. In dire need of new technologies for the implementation of the contents of teaching mathematics.

By using the latest achievements of modern information technology, mathematics lessons with the organization of cognitive activities students can develop competence [18].

New technology gives teachers the opportunity to work on a regular basis.

Information learning technology, today occupies a special place in the ïntraktïvti board.

Students can use the interactive whiteboard special program of new materials as much as possible. Its goal is to increase the student's ability to think on their own and teach the current and future work of modern interactive whiteboard. 
New technologies will be the organizer of the kind of creative activity of students' cognitive activity [19].

\section{References}

[1] "New technology elements." // Mathematics and Physics. 2004 - No. 6. -B.12-13.

[2] "Algebra use the computer during the course". // Mathematics and Physics. 2005. -№ 6. -B.15-16.

[3] "New technology in schools". // Mathematics and Physics. 2009. No. 2.

[4] Steel, S., S. Krwtïs "Critical thinking technology." // School teacher. 2007. -B.26-27.

[5] Qadaşeva. "Methods of teaching mathematics", Almaty, 2002. -B.19-20.

[6] "Information Technology". // Mathematics and Physics. 2008 - No. 6.

[7] Journal. "Mathematics", 2007. No. 5. -B.12-13.

[8] Kuanbaev B. The role of improving the system of formation of educational motivation. // Mathematics and Physics. 2005 - No. 2. -B.21-23.

[9] TS Sabirov "Educational technology". - National Publishing House, 1993. -B.53-54.

[10] I.J.Esenğabilov. 7 to teach students to solve mathematical problems. // "The lessons of the Nation". The Ministry of Education and Science Journal. Almaty, 2007.- No. 6. -B.41-43.

[11] Fundamentals of psychological development of pupils' mathematical skills to produce reports. // "In the high school." The Ministry of Education and Science Journal. - Almaty, 2007.- No. 1. B.65.

[12] Baimukhanov B. The use of information and computer technology as a tool for teaching algebra class. // Part of the credit system of education "International scientific-practical conference. Taldıqorğan, 2009. -B.211-213.

[13] "The theory and methodology of teaching Matematkan1 (Part 1, e-books). - Shymkent, 2007. B.110-112.

[14] The basis of formation of mathematical concepts in a secondary school teaching. // "High school" in the international scientific and educational publications. - Almaty, 2005. No. 2.

[15] "school" magazine, 2005. - No. 1. -B.66-67.

[16] "New information technology, mathematics sabğında". // "Science, Physics, Mathematics" magazine. 1997. No. 3. -B.10-11.

[17] "The use of new information technologies in teaching mathematics." // "Mathematics and Physics" scientific journal. 2003 - No. 6. -B.8-10.

[18] "Technology". // "IPM" scientific journal. 1999. -№ 5. -B.5-7.

[19] "The basis of the new technologies to improve the quality of education." // "IPM" scientific journal. 1993. No. 2. -B.10-13.

[20] Nurkasymova S. N., Mubarakov A. M., Sydykova J. K., Zhanys A. B. Outcome of the special problems of plant science related discipline and methods of teaching physical -matematicheskih problems with logical tasks. Wulfenia. ISSN 1561-882X, No.12, volume 23, Dec 2016, KLAGENFURT, AUSTRIA.

\footnotetext{
*Corresponding author.

E-mail address: aray.zhanys@gmail.com
} 